\title{
O pensamento de Antonio Gramsci e as políticas educacionais na atualidade
}

Maria Josélia Zanlorenzi

Universidade Estadual do Centro-Oeste

\section{SCHLESENER, Anita Helena (org.). Filosofia, política e educação:} leituras de Antonio Gramsci. Curitiba: UTP, 2014.

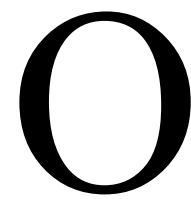

livro aqui resenhado é resultado de estudos que analisam as políticas educacionais na perspectiva de Antonio Gramsci e têm como objetivo compreender as relações sociais hegemônicas e suas influências na elaboração das políticas educacionais na atualidade. Os conceitos de Gramsci são abordados nessa obra por diferentes autores, os quais refletem sobre as relações de poder na sociedade capitalista.

No primeiro capítulo, intitulado Notas sobre hegemonia, Edmundo Fernandes Dias inicia sua discussão apontando o uso das palavras "liberdade", "igualdade", "cidadania" e "ordem" como vitais ao se tratar do discurso dos dominantes, mas que, quando separadas de sua problemática, podem provocar um erro de interpretação, ocasionando a alteração de sentido, além de produzir efeitos políticos contraditórios aos interesses da classe operária. Dias discute um dos conceitos centrais nos escritos de Gramsci - o de hegemonia. Esse conceito é utilizado por Gramsci como formação do consenso ou do consentimento da sociedade em vista de um projeto político. O consenso utilizado enquanto discurso atua de modo a capturar a subjetividade do antagonista pelos burgueses. $\mathrm{O}$ discurso, nas discussões de Edmundo Fernandes Dias, é utilizado para a preservação do capital, sendo um dos mecanismos ideológicos que se fazem necessários aos dominantes para combate à concepção teórica de classes. Para que isso ocorra, aponta o autor, são necessárias a redução do processo histórico e a

Filosofia e Educação [RFE] - Volume 9, Número 1 - Campinas, SP Fevereiro-Maio de 2017 - ISSN 1984-9605 - p. 197-203 
valorização de pequenos acontecimentos sem significado, acompanhados da desvinculação entre política e economia.

O segundo capítulo da obra, Gramsci e a Filosofia da Práxis, escrito por Rita Medici, explana o termo “popular” na filosofia da práxis. Aponta Medici que, por meio desse conceito, Gramsci refere-se a diversas ordens de problemas. A pesquisadora explica o uso do conceito "popular" nos escritos gramscianos, utilizando-se de modo preponderante de três termos: a) "literatura popular", que se refere à questão histórico-literária, expressão pouco considerada pelos pesquisadores de Gramsci, apesar de presente nas análises gramscianas e nos Cadernos do Cárcere; b) "cultura popular", uma expressão que alcança relevância maior nas análises de Gramsci e expressa as reflexões do filósofo sobre o "folclore" - este último, segundo Gramsci, devendo ser estudado como "concepção do mundo e da vida"; c) "ensaio popular", utilizado por Gramsci para entender o marxismo como "filosofia da práxis", a qual define como uma concepção do mundo de novo tipo que, embora sendo uma ideologia, "tende à superação de todas as ideologias" (p. 46).

Anita Helena Schlesener, no terceiro capítulo, intitulado Hegemonia e Educação: os princípios gnosiológicos do pensamento e da ação, ao abordar o conceito de hegemonia nos Cadernos do Cárcere, também o refere ao processo de formação do consenso ou do consentimento da sociedade como forma de dominação. Utiliza-se do conceito de hegemonia para discutir o movimento do real enquanto estrutura, em que a aparência, em sua composição, oculta a correlação de forças enquanto característica de uma sociedade dividida em classes. Salienta a necessidade de que, para entender o conceito de hegemonia, deve-se ter como base de reflexão a unidade entre economia, política e filosofia. Posicionamento utilizado por Gramsci em sua época para compreender a formação social e a dominação 
hegemônica na sociedade. $\mathrm{O}$ entendimento de tal relação e da tessitura política do domínio hegemônico pela classe burguesa deve passar também pelo entendimento da estrutura do Estado Moderno, bem como de sua forma de consolidar-se para manter o poder instituído, o qual passa pela combinação de dominação e direção intelectual e moral.

O capítulo escrito por Daniela Mussi, Clivagem da relação entre política e educação na Itália: o début de Antonio Gramsci, apresenta o cenário político, econômico e social da Itália no início do século XX. Esse momento foi fértil na luta dos trabalhadores na cidade e no campo no que concerne à questão política. Além disso, nesse período, as questões intelectuais foram marcadas pelo "renascimento do idealismo" que desencadeou o surgimento de diversos periódicos que discutiam as questões sociais da época na Itália. Gramsci, nesse cenário favorável, de expressão das ideias pela imprensa, manifesta sua interpretação política ao considerar que "todo o trabalho de preparação do movimento revolucionário, implicava um intenso trabalho de crítica" (p. 96).

Leandro Galastri, em Hegemonia como processo pedagógico: o Estado capitalista e a reprodução da ideologia, apresenta a luta como possibilidade para construir uma nova hegemonia, luta essa que deve explorar as oportunidades de expandir as práticas políticas para as classes trabalhadoras no que concerne à formação social na qual predomina o modo de produção capitalista. Em sua discussão, Galastri busca articular a convergência teórica entre Gramsci e Nico Poulantzas referente à leitura estrutural do marxismo,da educação e de sua relação com a hegemonia.

A contribuição de Marcos Del Roio, A educação como forma de reprodução da hegemonia e seu avesso, ilustra a obra, mostrando a preocupação de Gramsci com a escola, a educação e a cultura - elementos que se fizeram permanentemente presentes no desenvolvimento da teoria 
social e política elaborada por Gramsci. Relata o texto a experiência de autogestão vivenciada pela classe operária, na qual Gramsci estava envolvido. A autogestão é um modelo de educação pela qual a classe trabalhadora gera seus próprios intelectuais e seus dirigentes com o objetivo de contribuir para a elevação cultural. Destaca ainda Del Roio a importância da formação do partido revolucionário como educador das massas, mas, para que isso aconteça, seria necessária uma educação científica e cultural autônoma, pois "na medida em que a classe educa o partido, o partido educa a classe num processo organizativo e cultural de grande monta - a classe se faz partido e se prepara para se fazer Estado" (p. 126). O Estado operário, resultado da educação da classe que se faz partido, conduzido pela hegemonia do trabalho, daria origem a uma nova cultura que, pela filosofia da práxis, criaria o homem omnilateral e emancipado. A partir desse movimento, em consequência aconteceria a superação da divisão social do trabalho,condição para se alcançar o comunismo.

Dermeval Saviani, no capítulo Gramsci e a educação no Brasil: para uma teoria gramsciana da educação e da escola, faz um estudo das obras de Gramsci publicadas no Brasil e daquelas que discutem a educação na perspectiva gramsciana. Saviani explica que, para compreendermos como Gramsci concebe a educação, devemos primeiramente passar por sua concepção de homem. Explicita Saviani que o homem, segundo essa concepção, é um processo, mais especificamente, processo de seus próprios atos. Outro conceito abordado por Saviani na educação é a questão dos intelectuais, pelo qual Gramsci rompe com a divisão entre o trabalho manual e intelectual, pois toda a atividade humana requer o ato de pensar.

O oitavo capítulo, Gramsci e as atuais disputas pela educação profissional no Brasil, escrito por Maria de Fátima Rodrigues Pereira, menciona a produção de Gramsci bem como sua vida militante socialista 
como objeto de estudo na atualidade. Os escritos de Gramsci, segundo Pereira, são organizado em quatro períodos, sendo o primeiro pertencente ao final da Primeira Guerra Mundial, momento marcado por sua produção teórico-política e atividades jornalísticas. O segundo corresponde aos anos de 1919 e 1920, representados pela defesa da revolução socialista, que deveria ir além da tomada do poder governamental burguês; para se alcançar tal objetivo, deve-se contar com formação política, dimensão pedagógica para a formação da classe trabalhadora. O terceiro período de seus escritos corresponde aos anos de 1921 a 1926, o qual compreende o momento de ascensão do fascismo na Itália, quando Gramsci reflete sobre o Partido Comunista Italiano. Já o quarto período a autora o relaciona aos escritos de Gramsci encarcerado pelo governo de Benito Mussolini. No que concerne ao ensino profissional no Brasil, reflete a autora que sempre existiu educação para o trabalho, independentemente do regime político instaurado. A educação dual sempre prevaleceu, consequência da apropriação privada dos meios de produção, afirma a autora.

Marcos Vinícius Pansardi, no capítulo Aspectos de uma revolução passiva: a educação no governo Lula, ressalta o fato de estarmos em um momento de ressurgimento das ideias desenvolvimentistas do período de 1960, tendo essa política características da permanência do capitalismo dependente. Pansardi interpreta tais políticas a partir do conceito de "transformismo" para expressar a permanência do sistema capitalista e das políticas na atualidade. O pesquisador utiliza o conceito de "revolução passiva" com o intuito de caracterizar e contextualizar o governo Lula na lógica dos "pares contraditórios", o que significa uma aliança reformista de conservação das estruturas político-econômicas que visa a promover e manter a aliança entre a burguesia e a classe trabalhadora.

Filosofia e Educação [RFE] - Volume 9, Número 1 - Campinas, SP

Fevereiro-Maio de 2017 - ISSN 1984-9605 - p. 197-203 
O pensamento de Gramsci e as políticas públicas educacionais para o ensino médio: limites, dilemas e aproximações é o título do texto que apresenta uma reflexão sobre o Ensino Médio no Brasil, no qual os autores, Valéria Arias e Geraldo Balduino Horn, discutem as políticas públicas para o Ensino Médio. Os estudiosos mostram os limites das políticas educacionais e as possibilidades transformadoras da escola unitária em Gramsci como estratégia teórico-prática para a elaboração de um enfretamento político às tendências atuais presentes na escola pública em relação ao Ensino Médio. Ressaltam ainda o significado da cultura e da importância dos professores e gestores, como intelectuais organizadores e homogeneizadores da mesma classe, assim como salientam ser a escola, a educação e as políticas educacionais objetos de preocupação dos filósofos e educadores que, embora não únicos, são importantes nos espaços de produção e disseminação do projeto de transformação.

No último trabalho apresentado pela obra, Os fundamentos teóricoepistemológicos da teoria gramisciana e a pesquisa em políticas educacionais: primeiras aproximações, Maria de Lourdes Pinto de Almeida discute as formulações das políticas educacionais como luta hegemônica e pontua ser essa elaboração responsabilidade dos intelectuais. A pesquisadora defende que a filosofia da práxis é o crivo para compreender a atividade intelectual, sua correlação com as forças econômicas e o papel do pesquisador como intelectual orgânico para compreender os nexos entre o mundo do trabalho, as forças hegemônicas e academia, bem como o compromisso dos intelectuais e a pesquisa das políticas educacionais com a libertação do trabalhador em relação ao capital. Nesse contexto, os intelectuais, com seu discurso, desvelam ou consolidam as relações de poder existentes. No cenário educacional, o compromisso político do intelectual se consolida na elaboração e na consolidação das políticas educacionais, pois 
as mesmas mostram as relações das forças sociais de manutenção ou transformação da realidade em seus amplos aspectos.

A obra como um todo apresenta significativas contribuições para a compreensão da elaboração das políticas educacionais e as relações com as forças hegemônicas existentes na sociedade. Os textos contribuem para conhecer a influência do capital e o papel do Estado na elaboração das políticas públicas. Constitui-se numa referência para os estudiosos em Filosofia e Educação que pretendem fazer uma leitura da sociedade à luz dos conceitos gramscianos de educação, escola e políticas públicas. 